\title{
Estudio de la interacción química y bactericida de las nanopartículas de óxido de zinc frente a Staphylococcus aureus
}

\author{
Study of the chemical and bactericide interaction of zinc oxide nanoparticles \\ against Staphylococcus aureus

\begin{abstract}
Jorge Luis Zegarra Pumacayo ${ }^{1, a}$, Ana María Osorio Anaya ${ }^{1, b}$, Raymundo Erazo Erazo ${ }^{1, c}$, Fanny Blas Rodriguez ${ }^{1, \mathrm{~d}}$, Efraín Oscar Ninan Manga ${ }^{1, \mathrm{e}}$, Oscar Alberto Cornejo Sanchez ${ }^{1, \mathrm{f}}$, Joaquín Joaquín Manrique Fajardo ${ }^{1, g}$
\end{abstract}

Recibido: 15/04/2021 - Aprobado: 13/09/2021 - Publicado: 23/12/2021

\begin{abstract}
RESUMEN
Las aguas de los ríos, mares y lagunas contaminadas por diversas fuentes ya sea de origen natural o antropogénica, contienen sustancias contaminantes, entre ellas presentan alta carga bacteriana, que no posibilita el consumo humano por generar daños a la salud humana. Por ello, la investigación realizada presenta el estudio del efecto fotocatalítico de las nanopartículas de óxido de zinc (ZnONPS) como su mecanismo de interacción bioquímica con la consiguiente formación de las especies reactivas del oxígeno (ERO) y con ello proponer la interpretación de su posterior efecto bactericida al generar daño celular en las bacterias Staphylococcus aureus. Según los resultados obtenidos en un trabajo piloto experimental se reportó la disminución de la formación de colonias evaluado a través del método de cultivo en placa, y se determinó que la concentración de 10-4 $\mathrm{g}$ de $\mathrm{ZnONPs} / \mathrm{mL}$ (sintetizadas por el método de la precipitación) de tamaño aproximado de $29 \mathrm{~nm}$ frente a las bacterias Staphylococcus aureus ATCC 25923 presentó una cantidad menor a 1 UFC/g al concluir el análisis.
\end{abstract}

Palabras claves: Aguas contaminadas; Nanopartículas de óxido de zinc; Staphylococcus aureus; efecto fotocatalítico; especies reactivas del oxígeno.

\begin{abstract}
The waters of rivers, seas and lagoons contaminated by various sources, whether of natural or anthropogenic origin, contain polluting substances, among them they present a high bacterial load, which does not allow human consumption because it causes damage to human health. Therefore, the research carried out presents the study of the photocatalytic effect of zinc oxide nanoparticles (ZnONPS) as its mechanism of biochemical interaction with the consequent formation of reactive oxygen substances (ROS) and thus propose the interpretation of its subsequent Bactericidal effect by generating cellular damage in Staphylococcus aureus bacteria. According to the results obtained in an experimental pilot work, the decrease in colony formation evaluated through the plate culture method was reported, and it was determined that the concentration of $10-4 \mathrm{~g}$ of $\mathrm{ZnONPs} / \mathrm{mL}$ of ZnO nanoparticles (synthesized by the precipitation method) of size $29 \mathrm{~nm}$ against Staphylococcus aureus bacteria ATCC 25923 presented an amount less than $1 \mathrm{CFU} / \mathrm{g}$ at the end of the analysis.
\end{abstract}

Keywords: Polluted waters; zinc oxide nanoparticles; Staphylococcus aureus; photocatalytic effect; reactive oxygen species.

\footnotetext{
1 Universidad Nacional Mayor de San Marcos, Lima, Perú.

a Autor de correspondencia: jzegarrap2@unmsm.edu.pe - ORCID: https://orcid.org/0000-0003-0070-3569

b E-mail: aosorioa@unmsm.edu.pe - ORCID: https://orcid.org/0000-0002-4384-4671

c E-mail: rerazoe@unmsm.edu.pe - ORCID: https://orcid.org/0000-0003-1480-7641

E-mail: fblasr@unmsm.edu.pe - ORCID: https://orcid.org/0000-0002-9192-3438

E-mail: eninanm@unmsm.edu.pe - ORCID: https://orcid.org/0000-0003-0159-638X

E-mail: ocornejos@unmsm.edu.pe - ORCID: https://orcid.org/0000-0002-3388-8216

g E-mail: $\underline{12070122 @ \text { unmsm.edu.pe - ORCID: https://orcid.org/0000-0002-8173-9688 }}$
} 


\section{INTRODUCCIÓN}

Las bacterias desde el punto de vista patológico representan un serio problema para la historia de la salud en la humanidad, problema que conlleva a una cantidad de muertes en todo el mundo por las infecciones que causa sin importar la edad, sexo o alguna otra condición. Si bien en el siglo XX se empezó a sintetizar muchos antibióticos, estos también vienen siendo cada vez menos efectivos por el efecto mutagénico de las bacterias, es decir, generar resistencia al efecto bactericida, siendo muchas incluso multirresistentes en la actualidad. Es así como el Premio Nobel de Medicina, Sir Alexander Fleming (descubridor la penicilina), advertía el continuo uso de la penicilina acabaría provocando la resistencia de las bacterias, es así que, en el año 1945, el 14 $\%$ de las bacterias Staphylococcus aureus eran resistentes a la penicilina, posteriormente en el año 1995 el porcentaje se elevó a 95 \% (Harrod Buhner, 2007).

Por otro lado, en la actualidad tenemos en muchas zonas rurales en los países del mundo, un serio problema con el abastecimiento de agua para consumo humano, es decir, las aguas no están libres de sustancias contaminantes y microorganismos, y pueden generar un serio daño a la población (Lucas, L \& Carreño, 2019). Las aguas residuales son muy contaminantes y son causados por efluentes de las actividades humanas, sus actividades contaminan a las aguas naturales dejándolas no aptas para el consumo humano, por ello se continúa investigando su tratamiento (Cuba Tello et al., 2019). Estas aguas contaminadas son por lo tanto una gran preocupación en la sociedad y vienen siendo estudiadas para su posible tratamiento, por ejemplo, muchas actividades humanas consumen grandes cantidades de agua entre ellas la industria textil, las lavanderías, entre otras, y se están estudiando procesos para su tratamiento como los procesos de oxidación catalítica para disminuir su carga contaminante (Tolentino Castillo et al., 2019). Las nanopartículas de óxido de zinc en las últimas décadas están siendo estudiadas por su innovación tecnológica en diferentes áreas de la industria de los semiconductores, cosméticos, bloqueadores solares, catalizadores, pinturas anticorrosivas, adhesivos, vulcanización, descontaminación de colorantes orgánicos en efluentes, entre otros. En la Figura 1, se observa la estructura cristalina del óxido de zinc, tipo zincita y su coordinación tetraédrica se muestra en la figura 2, dicha coordinación 4:4 le otorga características particulares.

En los últimos años, el desarrollo de la nanotecnología nos permite estudiar otras opciones aplicativas para estos nanomateriales, debido a sus características particulares a

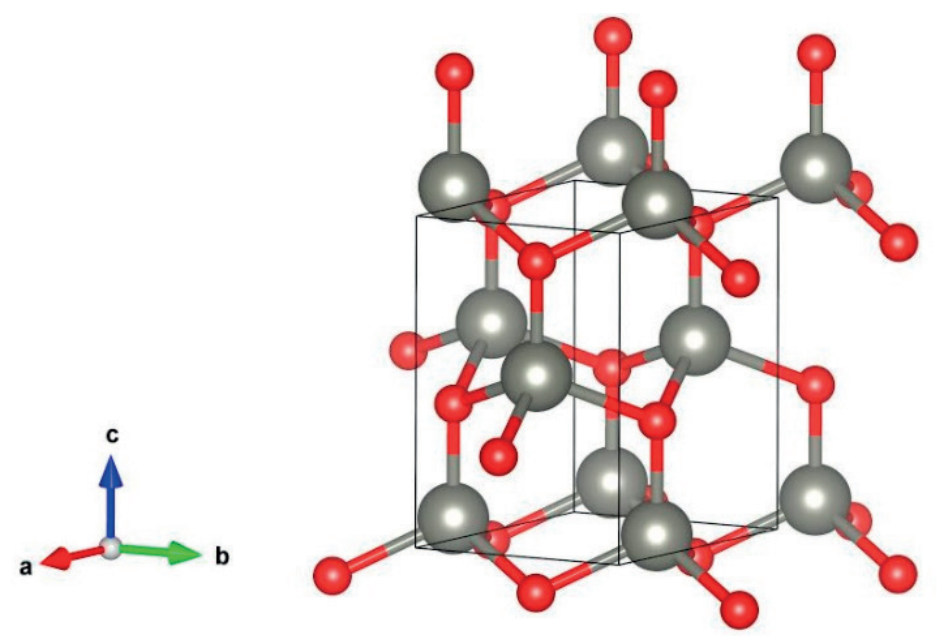

Figura 1. Estructura cristalina de la zincita $(\mathrm{ZnO})$ Nota: Estructura de la zincita realizado en VESTA (Momma \& Izumi, 2011) Fuente: Elaboración propia

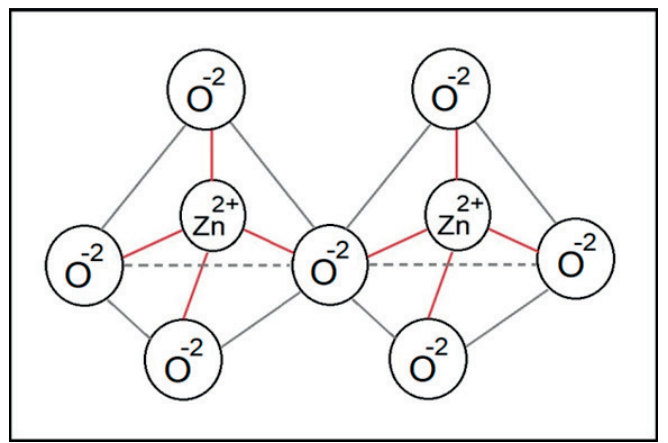

Figura 2. Estructura de coordinación tetraédrica de la estructura cristalina del $\mathrm{ZnO}$

Fuente: Elaboración propia 
dicha escala, porello, sepresenta en esteestudiolainteracción química del efecto bactericida de la nanopartícula de óxido de zinc en la bacteria Staphylococcus aureus.

Las nanopartículas de óxido de zinc tienen una sensibilidad por la luz ultravioleta (UV), esto le permite una actividad fotocatalítica porque esta radiación incidente tiene la capacidad de excitar a las nanopartículas de óxido de zinc, entonces este semiconductor puede llegar a obtener un comportamiento de conductor. La radiación incidente influye en los fotones de la banda de valencia del óxido de zinc, estos se desplazan a la banda de conducción, es decir, involucra un proceso oxido reducción. El estudio químico de la nanopartícula de óxido de zinc permite ver que la banda no permitida o también llamada prohibida tiene valores que permiten su excitación electrónica con radiación incidente. El óxido de zinc tiene una banda prohibida de 3,4 eV. (John L. Lyons et al., 2013) (J. L. Lyons et al., 2009). Esto proceso permitirá llevar a cabo un mecanismo de formación de las especies reactivas del oxígeno para otras reacciones químicas que involucran un daño en las células bacterianas.

El objetivo de la investigación es estudiar el mecanismo químico del efecto fotocatalítico, la formación de las especies reactivas del oxígeno en las nanopartículas de óxido de zinc, y realizar la medición experimental de su efecto bactericida en las bacterias Staphylococcus aureus.

Los resultados de la parte experimental nos indica un efecto bactericida por las nanopartículas usadas en cultivos de la bacteria Staphylococcus aureus, obteniéndose valores menores a 1,0 UFC/g para una concentración de $10^{-4} \mathrm{~g}$ de $\mathrm{ZnO} / \mathrm{mL}$.

\section{MATERIAL Y MÉTODOS}

La investigación se realizó aplicando el método descriptivo y experimental, para analizar el mecanismo químico de la formación de las especies reactivas del oxígeno y el análisis microbiológico de las bacterias Staphylococcus aureus con las nanopartículas de óxido de zinc, estas nanopartículas fueron sintetizadas por el método de precipitación en el Laboratorio de Nanotecnología e Innovación Tecnológica de la Facultad de Química e Ingeniería Química de la Universidad Nacional Mayor de San Marcos. Su caracterización se realizó por Difracción de Rayos X, a través del análisis instrumental y empleando la ecuación de Scherrer se determinó un tamaño promedio de $29 \mathrm{~nm}$. Se realizó el análisis del efecto antimicrobiano en el laboratorio de control de calidad de alimentos, agua y ambiente de la Facultad de Ciencias Biológicas de la Universidad Nacional Mayor de San Marcos.

\section{RESULTADOS}

Los resultados del tratamiento con las diferentes concentraciones de las nanopartículas de óxido de zinc se muestran en la Tabla 1, determinando los valores de las unidades formadoras de colonias de la bacteria Staphylococcus aureus. Por otro lado, en la Tabla 2 se indican los resultados en función al crecimiento y no crecimiento de las bacterias Staphylococcus aureus por las nanopartículas de óxido de zinc.

\section{DISCUSIÓN}

\subsection{Interacción Química}

Se encontró que las nanopartículas de óxido de zinc presentan un efecto bactericida a determinadas concentraciones de su tratamiento, es decir a determinada cantidad de carga biológica contaminante (Staphylococcus aureus). Esto se verificó con el valor del parámetro de las unidades formadoras de colonias de bacterias Staphylococcus aureus por gramo (UFC/g), también podemos corroborar en referencia de los resultados del análisis de laboratorio, un no crecimiento a determinada dilución con las nanopartículas $\left(10^{-4} \mathrm{~g}\right.$ de $\left.\mathrm{ZnO} / \mathrm{mL}\right)$.

Tabla 1. Unidades formadoras de colonias de bacterias Staphylococcus aureus por gramo (UFC/g) a diferentes concentraciones (diluciones) por el método de cultivo en placa

\begin{tabular}{|c|c|c|c|c|}
\hline \multirow{2}{*}{ Microorganismo } & \multicolumn{4}{|c|}{ Diluciones (g ZnONPS/mL) } \\
\hline & 0,1 & 0,01 & 0,001 & 0,0001 \\
\hline Staphylococcus aureus ATCC 25923 & Incontables & $286 \mathrm{UFC} / \mathrm{g}$ & $27 \mathrm{UFC} / \mathrm{g}$ & $<1 \mathrm{UFC} / \mathrm{g}$ \\
\hline
\end{tabular}

Fuente: Resultados del Análisis Microbiológico, Staphylococcus aureus. ICMSF Vol. 1. Método 1. 231-238. 2000, por el Laboratorio de control de calidad de alimentos, aguas y ambiente. Facultad de Ciencias Biológicas-UNMSM.

Tabla 2. Efecto de las nanopartículas de óxido de zinc en el crecimiento de la bacteria Staphylococcus aureus

\begin{tabular}{lcccc}
\hline \multirow{2}{*}{ Microorganismo } & \multicolumn{4}{c}{ Diluciones (g ZnONPS/mL) } \\
\cline { 4 - 6 } \cline { 3 - 5 } Staphylococcus aureus ATCC 25923 & 0,1 & 0,01 & 0,001 & 0,0001 \\
no crecimiento: - & +++ & ++ & + & - \\
crecimiento: $\quad+$ & & & \\
\hline Fuente: Resultados del Análisis Microbiológico, Staphylococcus aureus. ICMSF Vol. 1. Método 1. 231-238. 2000, por el Laboratorio \\
de control de calidad de alimentos, aguas y ambiente. Facultad de Ciencias Biológicas-UNMSM
\end{tabular}

Fuente: Resultados del Análisis Microbiológico, Staphylococcus aureus. ICMSF Vol. 1. Método
de control de calidad de alimentos, aguas y ambiente. Facultad de Ciencias Biológicas-UNMSM 
Las nanopartículas de óxido de zinc contribuyen a la formación de especies reactivas del oxígeno, por un efecto fotocatalítico, las cuales tendrán un efecto dañino en las bacterias del tipo Staphylococcus aureus. Las especies reactivas del oxígeno son estudiadas en biología molecular y patología humana por su efecto dañino en las mitocondrias, que son organelas muy importantes en la obtención energética en la célula (Kumar Vinay et al., 2018).

Realizando un estudio del mecanismo del efecto foto catalítico, la radiación absorbida por el óxido de zinc considerando su característica como semiconductor ha sido estudiado así también como su aplicación industrial, es así como John L. Lyons et al. (2013) señala lo siguiente:

"Los semiconductores de óxido son una familia de materiales muy prometedora para aplicaciones de dispositivos electrónicos, que muestran propiedades físicas únicas. Sus intervalos de banda van desde el infrarrojo (IR) sobre el visible y hacia las regiones ultravioleta (UV) del espectro". (p. 1)

En la Figura 3, se pueden estudiar tres etapas importantes para evaluar el efecto fotocatalítico de las nanopartículas de óxido de zinc, estas son las siguientes:

\subsubsection{En la etapa 1}

Se inicia la excitación de la nanopartícula de óxido de zinc semiconductora por radiación incidente de una fuente externa.

\subsubsection{En la etapa 2}

Se genera el par electrón-hueco, siendo este evento el que origina los radicales libres (formación de las especies reactivas del oxígeno).

\subsubsection{En la etapa 3}

Los radicales libres como parte de las especies reactivas del oxígeno, realizarán el daño celular a la bacteria Staphylococcus aureus, provocando su muerte celular.

Según Shi et al. (2014), las ecuaciones químicas para obtención de especies reactivas del oxígeno a partir de las nanopartículas de óxido de zinc (ZnONPs) son las siguientes:

$$
\begin{aligned}
& \mathrm{ZnO}+\mathrm{h} \gamma \rightarrow \mathrm{ZnO}+e^{-}+h^{+} \\
& h^{+}+\mathrm{H}_{2} \mathrm{O} \quad \rightarrow \quad \mathrm{OH}+\mathrm{H}^{+} \\
& e^{-}+\mathrm{O}_{2} \quad \rightarrow \quad \mathrm{O}_{2}^{-} \\
& \mathrm{O}_{2}^{-}+2 \mathrm{H}^{+}+e^{-} \rightarrow \mathrm{H}_{2} \mathrm{O}_{2}
\end{aligned}
$$

Considerando para ello lo siguiente: $\mathrm{ZnO}$ : nanopartículas de óxido de zinc, hy: energía de fotón, $\mathrm{e}^{-}$: electrón, $\mathrm{h}^{+}$: estado vacío (hueco), $\mathrm{H}_{2} \mathrm{O}$ : molécula de agua, $\mathrm{HO}$ : radical hidroxilo, $\mathrm{H}^{+}$: Ion hidrógeno, $\mathrm{O}_{2}^{-}$: radical superóxido, $\mathrm{H}_{2} \mathrm{O}_{2}$ : peróxido de hidrógeno

\subsection{Interacción bioquímica (ZnONPS - Staphylococcus aureus): Evaluación bactericida}

Las especies reactivas del oxígeno: el radical superóxido $\left(\mathrm{O}_{2}^{-}\right)$y el radical hidroxilo $(\mathrm{HO})$ también serán generadoras del daño a la célula procariota estudiada. Por ejemplo, el radical superóxido $\left(\mathrm{O}_{2}^{-}\right)$es un fuerte oxidante de sustancias orgánicas: "El anión superóxido es una especie muy tóxica, generada intermediariamente o como producto de descomposición incompleta, en la transformación de oxígeno a agua" (Baran, 2009). Con respecto al radical hidroxilo $(H O)$ la literatura en materia de la química bioinorgánica es muy clara y menciona su gran poder oxidante: "Esta última especie, que es deficiente en electrones, es consecuentemente un oxidante poderoso e indiscriminado, así como un iniciador de reacciones por radicales libres" (Baran, 2009).

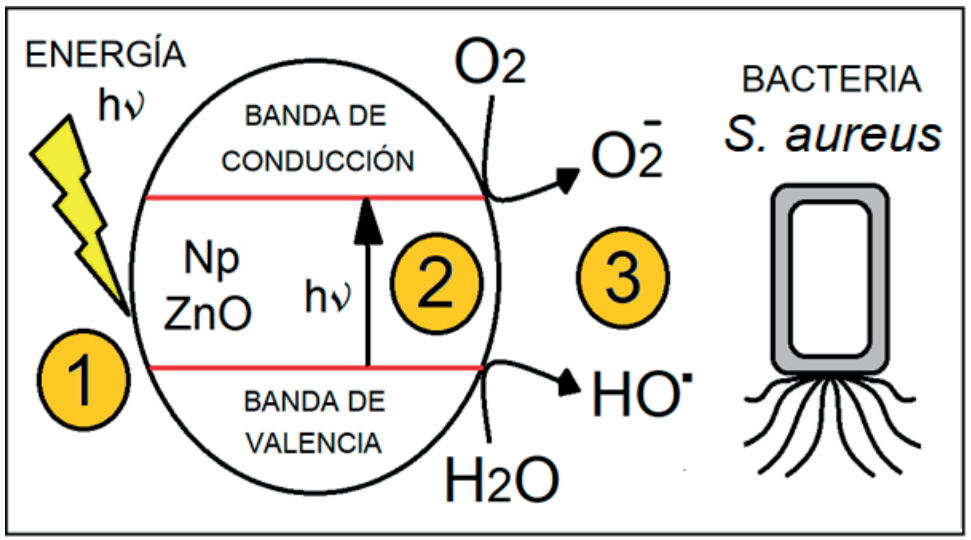

Figura 3. Actividad fotocatalítica de la nanopartícula de óxido de zinc para la obtención de las especies reactivas del oxígeno.

Nota: hy: energía de fotón, $\mathrm{O}_{2}$ : molécula de oxígeno, $\mathrm{O}_{2}^{-}$: radical superóxido, $\mathrm{H}_{2} \mathrm{O}$ : molécula de agua, $H O$ : radical hidroxilo.

Fuente: adaptado de Meenatchi et al. (2020) 
La estructura de la membrana bacteriana está formada por componentes orgánicos, hay presencia de biomoléculas que pueden ser dañadas por agentes oxidantes como las especies reactivas del oxígeno, generando su posterior muerte, (Pfaller et al., 2014) señalan lo siguiente:

La membrana citoplásmica posee una estructura lipídica de doble capa semejante a la observada en las membranas de los eucariotas, pero no contiene esferoides (p. ej., colesterol); una excepción a esta regla es las micoplasmas (p. 13).

Tomando en cuenta la presencia de dichas membranas celulares (composición estructural lipídica) y la presencia de las especies reactivas del oxígeno, otro autor como De Robertis (2015) señala:

Se sospecha que el anión superóxido produce mutaciones génicas y alteraciones en la bicapa lipídica de las membranas celulares, lo que podría acelerar el envejecimiento orgánico y facilitar la aparición de cuadros cancerígenos (p. 291).

Entonces el daño celular es realizado por las especies reactivas del oxígeno generadas en el proceso de fotocatálisis debido a las nanopartículas de óxido de zinc, ocasionando la muerte de las bacterias por dichas especies, debido a su gran poder oxidante en la materia orgánica (membrana celular de las bacterias).

\section{CONCLUSIÓN}

Se establece la existencia de una relación en el proceso del daño celular de las bacterias Staphylococcus aureus por la presencia de las nanopartículas de óxido de zinc, según el estudio químico realizado es debido a la formación de las especies reactivas del oxígeno (el radical superóxido $\left(\mathrm{O}_{2}^{-}\right.$ ), el radical hidroxilo $(H O \cdot)$ y el peróxido de hidrógeno $\left(\mathrm{H}_{2} \mathrm{O}_{2}\right)$. Esta formación es producto del efecto fotocatalítico de las nanopartículas de óxido de zinc con la interacción de la radiación que incide en dichas nanopartículas. Finalmente, se establece que para realizar un tratamiento de aguas contaminadas con microorganismos patógenos, se puede efectuar el uso de las nanopartículas de óxido de zinc, para el desarrollo una tecnología para disminuir el impacto ambiental, pero se debe seguir investigando para una futura obtención de líquidos con menor carga contaminante. Estas conclusiones se realizan según los resultados obtenidos del trabajo experimental en la cual se determinó valores menores a 1,0 UFC/g en las bacterias Staphylococcus aureus ATCC 25923, para la concentración de las nanopartículas de $\mathrm{ZnO}$ valor $10^{-4} \mathrm{~g}$ de $\mathrm{ZnO} / \mathrm{mL}$.

\section{AGRADECIMIENTOS}

Agradecer a las personas e instituciones que hicieron posible el desarrollo de la investigación: al Proyecto PCONFIGI C17071281 y al Proyecto PCONFIGI C19071481 del Vicerrectorado de Investigación de la Universidad Nacional Mayor de San Marcos; y a la Revista del Instituto de Investigación de la Facultad de Ingeniería Geológica,
Minera, Metalúrgica y Geográfica de la Universidad Nacional Mayor de San Marcos.

\section{REFERENCIAS}

Baran, E. J. (2009). Química bioinorgánica. Universidad Nacional Del Litoral Biblioteca Central Facultad de Ciencias Agrarias y Ciencias Veterinarias; McGraw-Hill/ Interamericana de España S.A. http://www.sidalc.net/cgibin/wxis.exe/?IsisScript=HAG.xis\&method=post\&formato $=2 \&$ cantidad $=1 \&$ expresion $=\mathrm{mfn}=005881$

Cuba Tello, M. V., Alcocer Meneses, P., \& Pacheco Ortíz, M. (2019). Tratamiento de agua residual procedente de lavadoras por el método de electrocoagulación para la reutilización en riego de vegetales - Ate Vitarte. Revista Del Instituto de Investigación de La Facultad de Minas, Metalurgia y Ciencias Geográficas, 22(44), 65-74. https:// doi.org/10.15381/iigeo.v1i1.17287

De Robertis, E. (2015). Biología Celular y Molecular. In El Ateneo. http://biblioteca.especializada.unjbg.edu.pe/ opac_css/index.php?lvl=notice_display\&id=1967\#.YUFVn223IU

Harrod Buhner, S. (2007). Antibióticos herbales: alternativas naturales para combatir las bacterias resistentes a los fármacos (E. O. (p. 17). España (ed.)). https://www. casadellibro.com/libro-antibioticos-herbales-alternativasnaturales-para-tratar-las-bacterias-farmaco-resistent es/9788484455660/2601249

Kumar Vinay, Abbas, A., \& Aster, J. (2018). Robbins. Patología humana - 10th Edition. Elsevier, 5, 952. https:// www.elsevier.com/books/robbins-patologia-humana/ kumar/978-84-9113-180-9

Lucas, L \& Carreño, Á. (2019). Calidad de agua de consumo humano en las comunidades balsa en medio, Julián y Severino de la microcuenca Carrizal, Ecuador. Revista Del Instituto de Investigaciones de La Facultad de Geología, Minas, Metalurgia y Ciencias Geográfica, 21(42), 39-46. https://doi.org/10.15381/iigeo.v21i42.15785

Lyons, J. L., Janotti, A., \& Van De Walle, C. G. (2009). Role of $\mathrm{Si}$ and $\mathrm{Ge}$ as impurities in ZnO. Physical Review B Condensed Matter and Materials Physics, 80(20). https:// doi.org/10.1103/PhysRevB.80.205113

Lyons, John L., Janotti, A., \& Van de Walle, C. G. (2013). Theory and Modeling of Oxide Semiconductors. In Semiconductors and Semimetals (Ed.), Semiconductors and Semimetals (Vol. 88, pp. 1-37). https://doi.org/10.1016/B978-0-12396489-2.00001-1

Meenatchi, T., Palanimurugan, A., Dhanalakshmi, A., Maheshkumar, V., \& Natarajan, B. (2020). Green synthesis of Cynodon Dactylon capped concentrations on $\mathrm{ZnO}$ nanoparticles for antibacterial activity, ROS/ML-DNA treatment and compilation of best controlling microbes by mathematical comparisons. Chemical Physics Letters, 749(16 June 2020), 137429. https://doi.org/10.1016/j. cplett.2020.137429

Momma, K., \& Izumi, F. (2011). VESTA 3 for three-dimensional visualization of crystal, volumetric and morphology data. Journal of Applied Crystallography, 44(6), 1272-1276. https://doi.org/10.1107/S0021889811038970 
Pfaller, M. A., Murray, P. R., \& Rosenthal, K. S. (2014) Microbiología médica. Elsevier 5ta Edición. https:// www.casadellibro.com/libro-microbiologia-medica-5ed/9788481749274/1086109

Shi, L. E., Li, Z. H., Zheng, W., Zhao, Y. F., Jin, Y. F., \& Tang, Z. X. (2014). Synthesis, antibacterial activity, antibacterial mechanism and food applications of $\mathrm{ZnO}$ nanoparticles: A review. In Food Additives and Contaminants - Part A Chemistry, Analysis, Control, Exposure and Risk Assessment (Vol. 31, Issue 2, pp. 173-186). https://doi.org/10.1080/194 40049.2013.865147
Tolentino Castillo, A. J., Benites Alfaro, E., \& Cabrera Carranza, C. (2019). Aguas residuales de lavandería y su tratamiento por Oxidación fotocatalítica con dióxido de titanio (TiO2) y luz ultra violeta (UV) en Instituto Nacional de Salud del Niño, San Borja- 2017. Revista Del Instituto de Investigación de La Facultad de Ingeniería Geológica, Minera, Metalurgica y Geográfica, 22(43). https://revistasinvestigacion.unmsm. edu.pe/index.php/iigeo/article/view/16680 